\title{
Planar Cell Polarity: Keeping Hairs Straight Is Not So Simple
}

\author{
Helen McNeill \\ Samuel Lunenfeld Research Institute, Department of Molecular Genetics, University of Toronto, \\ Toronto, Canada \\ Correspondence: mcneill@mshri.on.ca
}

The fur on a cat's back, the scales on a fish, or the bristles on a fly are all beautifully organized, with a high degree of polarization in their surface organization. Great progress has been made in understanding how individual cell polarity is established, but our understanding of how cells coordinate their polarity in forming coherent tissues is still fragmentary. The organization of cells in the plane of the epithelium is known as planar cell polarity (PCP), and studies in the past decade have delineated a genetic pathway for the control of PCP. This review will first briefly review data from the Drosophila field, where PCP was first identified and genetically characterized, and then explore how vertebrate tissues become polarized during development.

\section{DROSOPHILA PCP GENES, MUTANT PHENOTYPES, AND PATHWAY ANALYSIS}

D osophila PCP genes were first identified because of spontaneous mutations that caused a loss of organization in the surface bristles on the body, hairs on the wing, and photoreceptors in the eye (Fig. 1). Mutations in genes that affect PCP gave rise to a disorganized surface appearance and were named accordingly (for example, dishevelled [ $d s h]$ and frizzled $[f z]$ ) (Fahmy and Fahmy 1959; Gubb and Garcia-Bellido 1982). The distinctive swirls that occur in the wing of flies mutant for other PCP genes reminded their discoverers of the works of Vincent Van Gogh, leading to gene names such as van gogh (vang) (Taylor et al. 1998) and starry night (stan) (Chae et al. 1999). Genetic analysis indicated that these genes worked together and were needed for PCP in all tissues, thus they were named core PCP genes.

Core PCP genes include $d s h, f z$, vang, stan, prickle ( $p k$ ), and diego (dgo) (Feiguin et al. 2001). $f z$ encodes a seven-transmembrane receptor that functions as a receptor for Wingless $(\mathrm{Wg})$, and $d s h$ encodes a cytoplasmic transducer of the Wg pathway, implicating the Wnt pathway in PCP signaling and leading to the PCP pathway being referred to as the noncanonical Wnt pathway (for details of the canonical $\mathrm{Wg} / \mathrm{Wnt}$ pathway, see Cadigan and Peifer 2009). Loss of Wg does not affect planar polarity, so original models in Drosophila PCP speculated that another Wnt might be the instructive cue for PCP, and that a gradient of a Wnt might direct PCP establishment. A great deal of effort went into investigating

Editors: W. James Nelson and Elaine Fuchs

Additional Perspectives on Cell Junctions available at www.cshperspectives.org

Copyright (C) 2010 Cold Spring Harbor Laboratory Press; all rights reserved; doi: 10.1101/cshperspect.a003376

Cite this article as Cold Spring Harb Perspect Biol 2010;2:a003376 
H. McNeill

A

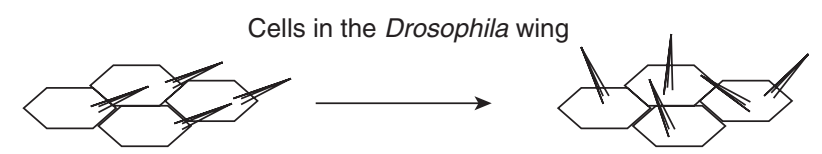

Ommatidia in the Drosophila eye

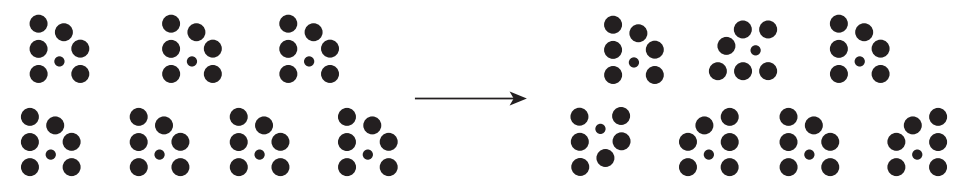

Normal

Planar polarity mutants

B

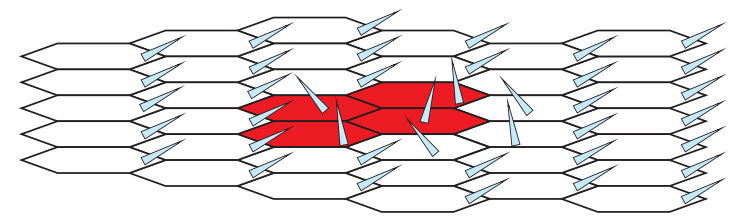

Proximal $\longleftrightarrow$ Distal

C

Pole

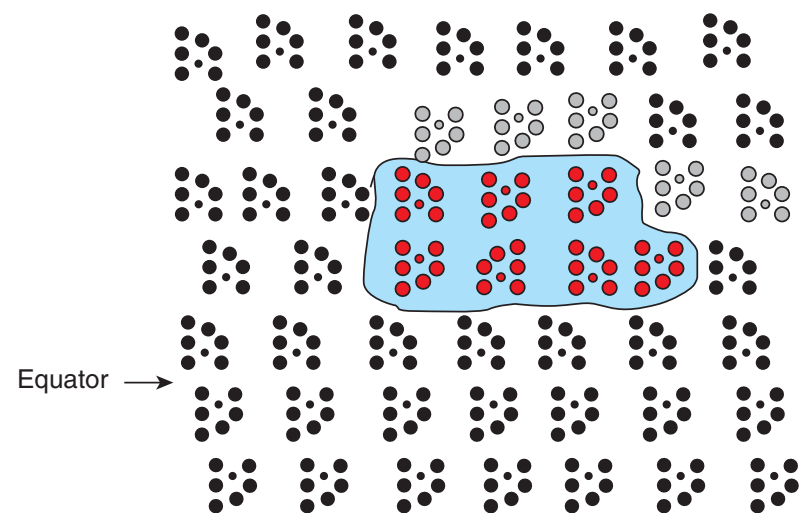

Figure 1. Planar polarity in the fly eye and wing. (A) Planar polarity can be clearly seen in the orientation of hairs on the wing of a fly (top) and in the orientation of photoreceptor clusters in sections of the fly eye (bottom). Mutations in PCP proteins results in loss of the planar organization of these tissues without affecting the cell fate or apical-basal polarity of the affected cells. Directional nonautonomy is a characteristic feature of PCP mutants. $(B)$ For example, loss of $f z$ in a clone of cells in the wing disrupts the polarity of mutant cells (marked in red) as well as wild-type cells on the distal side of the clones. Tissue on the proximal side is unaffected. (C) Similarly, loss of fat in a clone of cells in the eye ( $f a t$ mutant tissue is outlined) leads to disruptions of polarity on the polar side of the clone in genotypically wild-type tissue, whereas the equatorial side of the clone is unaffected (disrupted polarity of wild-type cells is shown in gray). 
this possibility, with largely negative results. Neither overexpression of different Wnts nor loss of function of multiple Wnts caused defects in planar polarity in the wing. Thus, current models (in Drosophila) have discounted the Wnts as instructive factors in PCP, however, vertebrate data suggests Wnts may also play permissive roles in PCP (see the following discussion).

The molecular nature of the other PCP genes reveals a diverse group of players. $p k$ and dgo encode cytoplasmic proteins (Gubb et al. 1999; Feiguin et al. 2001), whereas vang (also known as strabismus) encodes a four-pass transmembrane protein (Taylor et al. 1998; Wolff and Rubin 1998) and stan (also known as flamingo [ fmi]) encodes a seven-transmembrane protein with a large extracellular domain that contains multiple cadherin repeats (Usui et al. 1999). Fmi can engage in homotypic cell adhesion, and Fmi-based adhesions are essential for the establishment of PCP.

Core PCP proteins become localized to apical junctions early in development (Axelrod 2001; Bastock et al. 2003; Das et al. 2004; Jenny et al. 2003; Strutt et al. 2002; Tree et al. 2002). Strikingly, during pupal development this distribution becomes reorganized into an asymmetric distribution in the cell. This asymmetric localization occurs before any overt morphological evidence of PCP and is thought to be important for PCP signaling (reviewed in McNeill 2002). There are two distinct classes of asymmetric distribution: Fz, Dsh, and Dgo are localized to the distal side of each cell in the wing (where the hair will eventually emerge), whereas Vang and $\mathrm{Pk}$ are localized to the proximal side of each cell. Stan is localized to both proximal and distal ends of each hair cell (Fig. 2). There is a similar polarized localization of PCP proteins in the eye; however, the pattern is more complex, consistent with the more complex structure of the eye. Instead of an identical, repetitive pattern of proximal distal accumulation, core PCP proteins only accumulate in a subset of cells, most importantly at the photoreceptor R3/photoreceptor R4 interface.

Loss of any one of the core PCP genes leads to loss of the polarized localization of all the other components, suggesting complex positive and negative interactions. Supporting this is the finding of direct binding between many of the components, at least in in vitro settings: Diego and Pk bind Dsh (Tree et al. 2002; Jenny et al. 2003); Fmi binds Vang ( Wu and Mlodzik 2008) and Fz (Chen et al. 2008); and Vang binds $\mathrm{Pk}$ and Dsh (Bastock et al. 2003; Park and Moon 2002). Expression of $\mathrm{Fz}$ in tissue culture cells causes the recruitment of Dsh to the membrane (Axelrod et al. 1998; Axelrod 2001) and there are quite weak but direct interactions between Fz and Dsh (Wong et al. 2003). Together these findings suggest that multiple direct protein-protein interactions underlie the asymmetric distribution of the core PCP proteins. It is still very unclear, however, how the direction of the asymmetry is established.

Another set of genes are only needed in subsets of tissues to direct planar polarity: These tissue-specific PCP genes include genes such as multiple wing hair ( $m w h$ ) (Strutt and Warrington 2008), fuzzy ( fy) (Collier and Gubb 1997), and inturned (in) (Park et al. 1996), which are only needed for wing PCP, and mirror, fringe, and roulette, which are only necessary for PCP in the eye (Choi and Benzer 1994; McNeill et al. 1997; Cho and Choi 1998; Dominguez and de Celis 1998; Yang et al. 1999; Strutt and Strutt 2003).

A more recently discovered group of PCP genes include the large cadherins Fat and Dachsous (Ds) and the Golgi-associated kinase Four-jointed, and are referred to as the Fat/Ds/Fj PCP cassette (Zeidler et al. 1999; Casal et al. 2002; Rawls et al. 2002; Yang et al. 2002; Matakatsu and Blair 2004; Simon 2004). These genes regulate PCP in all tissues in Drosophila; however, they form a distinct class of PCP genes from the core genes. Unlike the core PCP proteins, Fat and Ds are not distributed asymmetrically in the cell-instead the expression of Ds is graded over the tissue. In the wing, Ds is expressed at high levels at the proximal region of the wing and is absent from the distal portions. Conversely, $\mathrm{Fj}$ is expressed strongly at the distal edge of the wing and expression fades toward the proximal region. Fat is expressed evenly throughout the 
H. McNeill
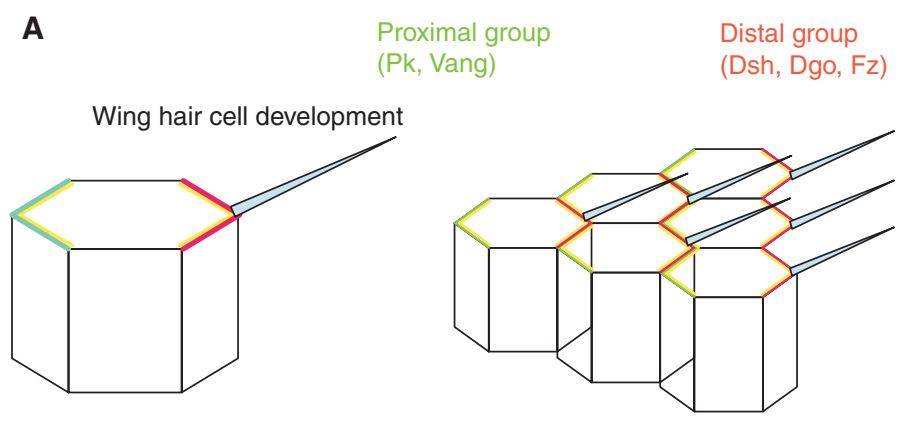

B Photoreceptor developmennt

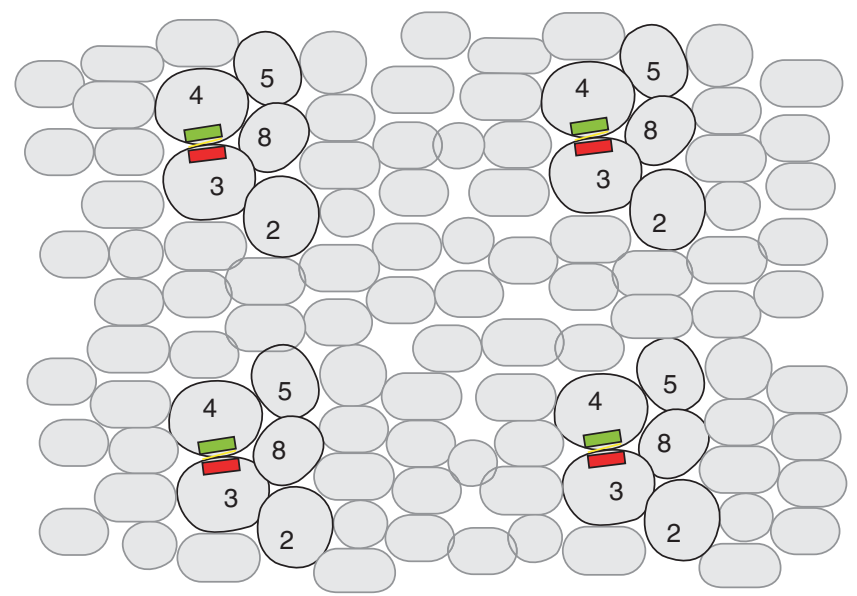

Figure 2. Asymmetry of core PCP proteins. During pupal development, the core PCP proteins become asymmetrically distributed in the plane of the epithelium. Fz, Dsh, and Dgo (shown in green) are enriched on the distal side of each cell, whereas Pk and Stbm (red) are enriched on the proximal side of each cell. Fmi (yellow) is enriched on both proximal and distal sides of each cell.

wing (Fig. 3). Current models propose that Ds binding to Fat inhibits Fat PCP activity (Yang et al. 2002; Ma et al. 2003). Fat regulates the expression of $f j$ via direct binding of the transcriptional repressor, Atrophin (Fanto et al. 2003). Original models of PCP suggested that the Fat/Ds/Fj cassette is upstream of the core PCP genes and directs their asymmetric distribution. This has been recently challenged (Casal et al. 2006), and it is currently unclear if the Fat/Ds cassette is upstream or in parallel of the core PCP, and if it is, how the information is propagated from one system to the other. Intriguingly, recent studies have shown that Fat binds to the kinase Dco (Sopko et al. 2009), which has been shown to regulate PCP via the core PCP protein Dsh (Strutt et al. 2006), providing a possible link between core and Fat/Ds PCP regulation. Interestingly, Fat forms cis-dimers and Ds binding to Fat promotes Fat dimerization and phosphorylation by Dco (Sopko et al. 2009). Recent data also indicates that the Fat/Ds cassette regulates tissue growth through the Hippo pathway (reviewed in Sopko and McNeill 2009), but the regulation of growth appears to be separable from the control of PCP.

\section{NONAUTONOMOUS PLANAR CELL POLARITY}

One of the most striking yet mysterious aspects of planar cell polarity is the phenomena known as domineering nonautonomy. Analysis of patches of mutant tissues (induced by recombination and called mosaic clones) revealed that 
A

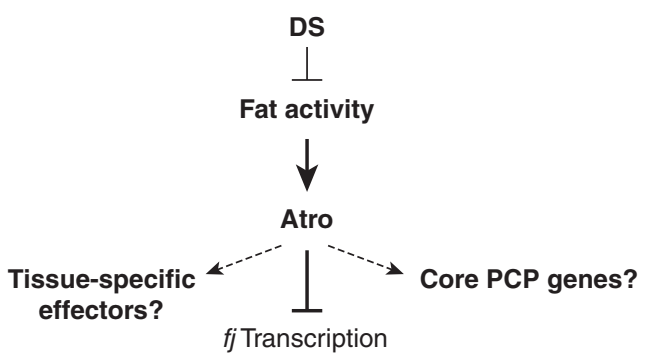

B
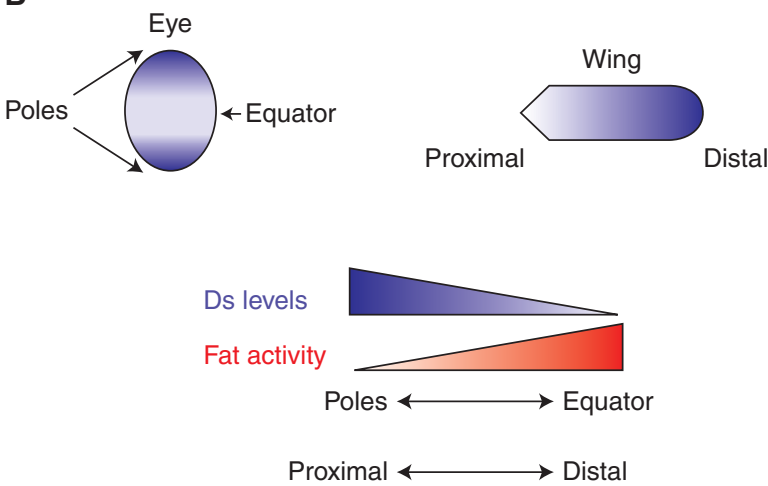

Figure 3. Fat and Ds model and gradients. Fat is a large cadherin that functions as a receptor for another large cadherin, Ds. Ds binding to Fat inhibits Fat activity. Ds is expressed in a gradient in the eye and the wing, resulting in an inverse gradient of Fat activity. Fat represses $f j$ transcription, acting through the transcriptional corepressor, Atrophin. The PCP effects of $f j$ mutants are much weaker than the PCP effects of loss of fat or atrophin, suggesting that there are other targets. One potential target is the activity of core PCP proteins such as Fz.

wild-type tissue bordering the mutant tissue lost polarity (Fig. 1). This phenomena is seen in all tissues, but is easiest to describe in the wing, which is planar polarized in the proximal-distal axis. The direction of the nonautonomy is consistent for each genotype: For $f z^{-/-}$ clones, wild-type cells distal to the clone lose planar polarization, but those proximal to the clone are normal (Vinson and Adler 1987). Conversely, clones of $\mathrm{Vang}^{-/-}$cells disrupt the organization of wild-type cells on the proximal side of clones, whereas distal cells are unaffected (Taylor et al. 1998). Nonautonomous disruptions of PCP are also seen with Fat/Ds/ $\mathrm{Fj}$ clones. In this case, clones of Ds disrupt polarity on the opposite side of the clones from clones of Fat, which is one of the arguments that Ds inhibits Fat activity in PCP. Interestingly, not all elements of the core PCP pathway display nonautonomous polarity defects: Clones of Dsh, Pk, Diego, and Fmi do not affect the polarity of adjacent wild-type cells (Strutt and Strutt 2007). In addition, there are separable mutations that affect $\mathrm{Fz}$ autonomous and nonautonomous PCP activity (Vinson and Adler 1987), and different times at which $\mathrm{Fz}$ autonomous and nonautonomous signaling function during development (Strutt and Strutt 2002). This has led to the proposal that there are separable cell-autonomous and -nonautonomous routes for PCP signal. The mechanistic basis of nonautonomous polarity is hotly contested at present (Chen et al. 2008; Lawrence et al. 2008; Strutt and Strutt 2008; Wu and Mlodzik 2008).

\section{MAMMALIAN PCP}

Mammalian tissues also show clear planar organization, and for many years it was 
H. McNeill

speculated that the coordinate organization of hair cells in the inner ear or the fur on an animal's back represented a similar process as Drosophila planar polarity (Eaton 1997) and might be subject to control by homologs of Drosophila PCP genes. This has been strongly supported by findings in the past few years. Loss of Fz6, for example, leads to disorganized hair on the back of a mouse with swirls that look strikingly similar to the swirls seen on the wing of a fly with mutations in PCP genes (Guo et al. 2004). Similarly, mutations in Vangl2 disrupt the coordinate organization of hair cells in the inner ear of mice (Montcouquiol et al. 2003). In depth analysis of the processes underlying the planar organization of these tissues has found some striking similarities between Drosophila and mammalian PCP establishment, but also some important differences.

\section{PLANAR POLARITY IN THE INNER EAR}

The inner ear is a complex structure that requires precise planar organization to carry out its function in hearing and in balance (Fig. 4). The cochlea is essential for hearing, whereas balance is dependent upon the otolith organs and semicircular canals. The organ of Corti, in the cochlea, contains of rows of sensory cells known as hair cells. Hair cells have apical microvilli-derived stereocila and a single primary cilium known as the kinocilium. The stereocilia and kinocilum form a V-shaped structure that is polarized across a field of hair cells. The cochlea has one row of inner hair cells and three rows of outer hair cells, which are interdigitated with support cells. The vertices of the hair bundles all point toward the periphery of the cochlea, thus displaying planar polarity. There is also a planar polarity of the sensory hair cells of the vestibular system, where, intriguingly, the hair cells "point" toward a central line of polarity reversal. This is reminiscent of the reversion of PCP that occurs at the equator of the fly eye.

The planar organization of hair cells in the inner ear is disrupted in a number of core PCP mutants, supporting the proposal that this coordinate organization is a form of vertebrate PCP. Mutation of Vangl2 (Montcouquiol et al. 2003; Qian et al. 2007; Torban et al. 2008) or Celsr1 (a homolog of Fmi/Stan) (Curtin et al. 2003) disrupts hair cell orientation. Single loss of
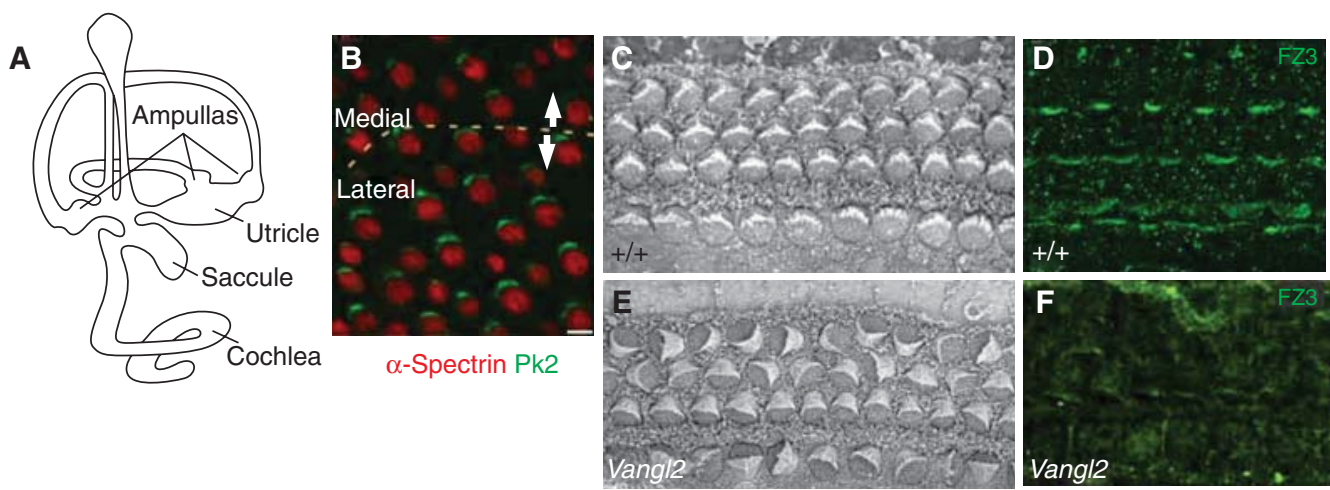

Figure 4. PCP in the vertebrate inner ear. (A) Structure of the inner ear. $(B)$ Cells in the saccule are planar polarized, with an inversion of polarity near the middle of the tissue. The planar polarity of cells is strikingly seen by staining with antibodies to Prickle 2, which light up one side of all the sensory cells ( $A$ and $B$ reprinted with permission from Deans et al. 2007). (C) Hair cells in the cochlea are characterized by apical actin-rich stereocilia and a single sensory cilum, known as a kinocilium. Hair cells are divided into three rows of outer hair cells and a single row of inner hair cells. All the stereocilia are polarized in the plane of the epithelium. This organization is lost in PCP mutants such as Vangl2 (E). Hair cell polarity is also seen with staining with antibodies to Frizzled, which stains one side of the cells, indicating the conserved planar polarity of the tissues $(D)$. This staining is lost in Vangl2 mutants $(F)$. (C-F reprinted, with permission, from Montcouquiol et al. 2003 [Macmillana], 2006.) 
other PCP genes does not cause planar defects in the ear, presumably because of redundancy between related family members. Consistent with this interpretation, Fz3;Fz6 double mutants (Wang et al. 2006) and Dvl1;2 double mutants have defective orientation of hair cells (Wang et al. 2005), although single mutants have normal inner ear PCP.

There are often strong genetic interactions between PCP genes in planar polarity of the inner ear. For example, $D v l 3^{-/-}$cochleas have only minor PCP defects and there are no detectable PCP defects in Vangl2 ${ }^{L p /+}$ cochlea, yet Dvl3 $3^{-/-} ;$Vangl $2^{L p /+}$ hair cells have dramatic misorientations of the hair cells (Etheridge et al. 2008). Loss of Fat4, the homolog of Drosophila Fat, also causes defects in orientation of hair cells of the inner ear (Saburi et al. 2008), although these effects are weaker than those found in $\mathrm{Vangl2} 2^{\mathrm{Lp} / \mathrm{Lp}}$ or $\mathrm{Celsr}^{-/-}$mutants. Thus the phenotypes of many mutants suggest that vertebrate homologs of Drosophila PCP genes control similar planar tissue organization. There may be some dependence on a variety of PCP genes in different portions of the ear.

Excitingly, close analysis of the inner ear has also shown that vertebrate core PCP proteins display asymmetric protein distribution, analogous to Drosophila core PCP proteins. Fz3 and Fz6 proteins are localized to the lateral faces of sensory and supporting cells in all sensory epithelia in a pattern that correlates with the axis of planar polarity (Wang et al. 2006). Vangl2, Dvl2, and Pk2 have also been shown to have asymmetric localization in vertebrates (Montcouquiol et al. 2006; Wang et al. 2006; Deans et al. 2007; Devenport and Fuchs 2008). Therefore, a polarized localization of PCP components is a conserved feature of the PCP signaling cascade. This suggests that the mechanism of asymmetric localization of PCP proteins is conserved and likely to play an important role in the establishment of planar polarized tissues. This asymmetry has been seen in other tissues and in other species: $\mathrm{Pk}$, for example, is asymmetric in the fish neural keel during early development (Ciruna et al. 2006).

And, as in flies, loss of components of the core pathway can disrupt the localization of other core PCP proteins: For example, loss of Vang12 leads to loss of polarized localization of Fz3 and Fz6 (Montcouquiol et al. 2006; Wang et al. 2006), again highlighting conservation of mechanisms between flies and mice. It is not a completely simple story, however, as some of the proteins that show distinct protein localizations in Drosophila are found in overlapping patterns in the mouse. For example, in flies, Fz and Dsh colocalize on the distal edges of hair cells, whereas $\mathrm{Pk}$ and Vang are localized to the proximal side of cells. It was surprising, therefore, to find that Vangl2, Fz, and Fz6 are found on the same side of inner ear sensory cells (Montcouquiol et al. 2006) in the mouse. Thus, the details of the implementation of the PCP signal may be more complicated in mammals, and one cannot simply extrapolate from the fly data.

\section{PLANAR POLARITY IN VERTEBRATE HAIR}

The sleek organization of hairs on the back of a horse or a mouse is clearly analogous to the hairs on a fly's wing, but very different in the underlying biology. Mammalian hairs are made up of groups of cells, whereas the hair on a flies wing is a single actin-rich extension present on each cell. Yet, satisfyingly, recent data has indicated that the planar organization of these very different tissues is controlled by the conserved PCP signaling molecules.

Initial studies showed that $\mathrm{Fz}^{-/-}$mice have disorganized fur and suggested that the strongest disorganization occurred with interspersed $\mathrm{Fz}^{-/-}$patches in chimeras (Guo et al. 2004). Inversin is a homolog of the core PCP protein Dgo, and inversin mutants have hair patterning defects similar to those observed in $\mathrm{Fz}^{-/-}$mice (Simons et al. 2005). More recent studies have shown that many core PCP genes are involved in establishing organization of hair in vertebrates (Devenport and Fuchs 2008). Fur is not visible on newborn mice, and loss of many PCP genes causes embryonic lethality. Thus the full contribution of PCP genes to planar organization of hair can only be seen in transplants and chimera experiments. 
H. McNeill

Hair formation begins in the mouse at E14.5. Inductive signals from the dermis cause placodes to bud from the overlying epithelium. Groups of cells aggregate and invade the dermis. Eventually, the entire structure becomes polarized in the plane of the epithelium with a resulting tilt that causes the hair to lay flat as it emerges. As the hair germ develops, cells on the anterior side constrict basally and more posterior cells become elongated and columnar. Clearly this is a process that is far more complicated than causing a single actin-rich cellular extension to arise from one side of the cell, as in the fly wing. It is perhaps more analogous to the development of polarity in the Drosophila eye, which also forms from clusters of cells that rotate $90^{\circ}$ to adopt their final morphological polarity. Although every cell in the fly wing shows a proximal-distal distribution of core PCP proteins, in the eye only a subset of cells display asymmetric core PCP protein distribution. In a similar manner, examination of the distribution of core PCP proteins in the developing epidermis revealed that Vangl2, Fz6, and Celsr 1 are asymmetrically distributed (Devenport and Fuchs 2008). Vangl2 and Celsr1 are restricted to the lateral sides of the basal epidermal cells and enriched along the anterior-posterior axis. In addition, there also appears to be a nonautonomous component to PCP, as chimeric experiments revealed that Vangl $2^{L p / L p}$ tissue disrupts the polarity of adjacent wild-type hair follicles.

\section{PLANAR POLARITY GENES CONTROL COORDINATE CELL MOVEMENTS AND PROMOTE LENGTHENING AND NARROWING OF TISSUES}

The planar polarity of the inner ear and of the fur of mammals is conceptually similar to the organization of cells in the wing and the eye of the fly. However, there are also novel PCP phenotypes in mammals that do not directly correlate with classic Drosophila PCP phenotypes. Most notable is the role of PCP genes in polarized cell movements needed to establish the correct shape of many organs, and even of animals. Loss of many PCP genes leads to problems in neural tube closure, eyelid closure, and cochlear extension. Underlying all of these defects is a loss of polarized cell movements that cause tissues to narrow and lengthen.

The first indications of a role for PCP proteins in this process were found in frogs and fish, where altering Dsh, Fz7, or Wnt11 disrupted the cell movements of convergent extension during gastrulation (Djiane et al. 2000; Heisenberg et al. 2000; Wallingford et al. 2000). This resulted in animals with short, broad tissues. Excitingly, point mutations in Dsh, which specifically altered PCP in flies, led to convergent-extension defects, thereby supporting the proposal that the morphogenetic defects observed were because of loss of PCP signaling. Altering Vang also lead to convergence and extension defects (Goto and Keller 2002). Because of these original observations, many other PCP components have been shown to affect convergence and extension movements in fish and frogs (reviewed in Tada and Kai 2009).

Analysis of mice mutants for various core PCP components soon revealed that the neural tube failed to close in many cases and that a lack of convergence and extension movements in the developing tissue underlies the neural tube closure defects. The neural tube closure defects are at times extreme (when they are called craniorachisis), or can be more subtle. Defects in neural tube closure are found in Vangl2 ${ }^{L p / L p}$ mutants (Kibar et al. 2001), Celsr mutants (Curtin et al. 2003), Fz3/Fz6 double mutants (Wang et al. 2005), and $D v l 1 / D v l 2$ double mutants. Early studies showed that the midline fails to narrow and extend properly in Vangl2 $2^{L p / L p}$ embryos. Although the neural folds form and elevate normally, they are spaced widely apart as a result of intervening cells that have not intercalated.

Many developmental defects caused by loss of convergence and extension movements occur in PCP mutants. One example is lack of eyelid closure. Eyelid closure normally occurs at about E16 in the mouse and, like neural tube closure, involves a medial convergence of a pair of flanking epithelial sheets. Defects in 
eyelid closure are found in Fz3,Fz6 mutants and Celsr mutants. A narrowing and lengthening analogous to convergent extension also occurs during development of the organ of Corti in the mammalian cochlea and this shape change fails to occur in Vangl2 mutants, Dvl1;Dvl2 double-mutants, Fz3;Fz6 double-mutants, and Fat4 mutants (Montcouquiol et al. 2003; Wang et al. 2005; Wang et al. 2006; Saburi et al. 2008). Thus shaping elongated tissues is a crucial role of many PCP genes.

\section{CYSTIC KIDNEY DISEASE AND VERTEBRATE PCP}

An unexpected defect caused by loss of PCP signaling is cystic kidney disease. One of the first indications of a link between cystic kidney disease and PCP in mammals was the finding that mutations in inversin cause cystic kidney disease. Inversin is a homolog of the core PCP protein Dgo, and controls the balance between canonical and noncanonical Wnt (PCP) signaling (Simons et al. 2005). This provided a potential link between PCP and cystic kidney disease. At that time, however, it was unclear how loss of normal PCP signaling might lead to cyst formation.

More recent studies have suggested how PCP signaling may function in normal kidney development and why defective PCP signaling causes cystic dilations of kidney tubules. Using cell lineage tracing and examination of cell in mitosis, it was shown that when tubular epithelial cells divide, there is a high degree of oriented cell division (Fischer et al. 2006): $95 \%$ of cells divide within $34^{\circ}$ of the axis of the tubule. This suggested that oriented cell division is essential for the normally thin elongated tubes that make up much of the nephron (Fig. 5). Importantly, two different mouse models of polycystic kidney disease display
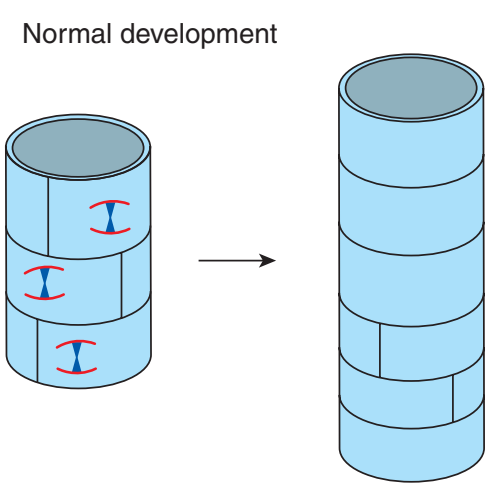

PCP or PKD mutants

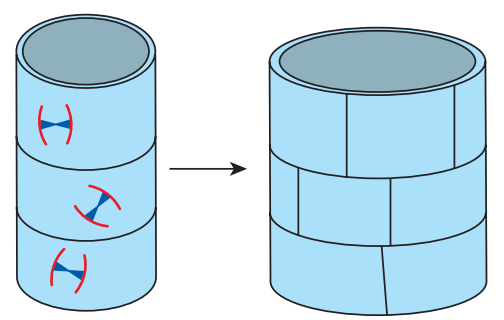

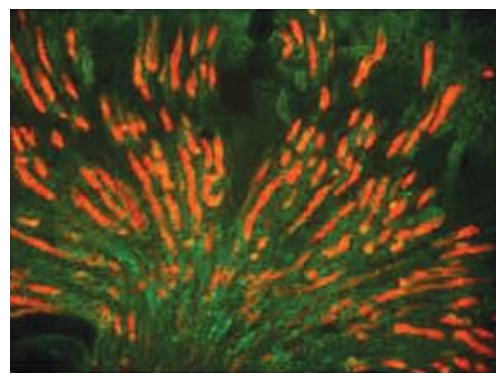

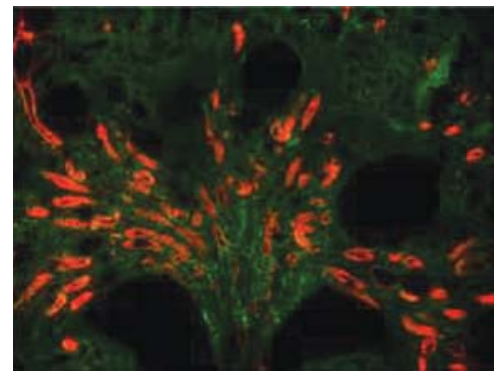

Figure 5. Oriented Cell division is lost in PCP mutants, leading to cyst formation. During normal development, epithelial cells in the kidney tubule have oriented division, resulting in an elongation of the tubule during development (top). In PCP mutants such as Fat4, this strict oriented cell division is lost, leading to a widening of the tubule diameter and eventually cyst formation (bottom). 
loss of oriented cell division. Previous studies had shown that loss of PCP genes leads to defects in oriented cell division in flies and in fish (Gho and Schweisguth 1998; Garoia et al. 2000; Bellaiche et al. 2001; Gong et al. 2004; Baena-Lopez et al. 2005). Given the known role of PCP signaling in oriented cell division, cystic kidney disease might be caused by defective PCP.

This hypothesis was recently strengthened by the observation that mutants in Fat4, an ortholog of Drosophila Fat, display many classic PCP phenotypes, including inner ear defects and neural tube defects (Saburi et al. 2008). The Fat/Ds/Fj signaling cassette seems to function in the same way in mice as in flies, because in Fat4 mutants, Fjx1, the fj ortholog is transcriptionally up-regulated, as it is in flies in fat mutants. Importantly, Fat4 mutant kidneys have dilated tubules and cysts. Analysis of the oriented cell division revealed that loss of Fat4 leads to randomization of spindle orientation at birth. The cystic phenotype of Fat 4 mutant kidneys was enhanced by loss of Fj ortholog, fjxl, as well as loss of one copy of the core PCP gene Vangl2, further supporting the hypothesis that loss of PCP signaling leads to cyst formation. Loss of Drosophila Fat leads to loss of oriented cell division in the wing, suggesting the role of Fat in controlling cell division is conserved (Baena-Lopez et al. 2005). Interestingly, Fat 4 is localized to the primary cilium, an organelle already implicated in polycystic kidney disease and in vertebrate PCP signaling.

The finding that the majority of protein products of cystic disease genes are localized on the primary cilia has led to the ciliary hypothesis of cystic disease (Kim and Walz 2007; Yoder 2007; Harris and Torres 2008). A potential role for cilia in the kidney is in flow sensing: Renal cilia project into the tubule lumen and will bend in response to fluid flow. Bending of the cilia stimulates an increase in cytosolic calcium concentration (Praetorius and Spring 2003) leading to the proposal that primary cilia function as mechanosensors of urine flow in the renal tubules, and that loss of flow sensing leads to cyst formation.
However, recent papers (Piontek et al. 2007; Patel et al. 2008) have challenged the notion that tubular geometry is maintained by the mechanical bending of cilia in response to flow. Intriguingly, recent data has suggested that PCP signaling may be linked to cilia function. Many ciliary proteins that have been linked to cystic disease, such as Bardel-Biedl syndrome and Oculo-Facial-Digital syndrome, also show PCP defects (Davenport and Yoder 2005; Ferrante et al. 2008; Ross et al. 2005). In addition, cyst formation in kidneys occurs when cilia are ablated, and, intriguingly, the control of oriented cell division is also lost in cells lacking cilia (Patel et al. 2008).

\section{CILIA AND PCP}

Many links have been made between PCP and cilia, although the exact nature of the relationship between these is still unclear. Loss of the PCP effector genes fuzzy and inturned leads to disruption of the cytoskeleton (Park et al. 2006) and defects in cilia formation. Ciliary associated proteins such as Inversin are thought to regulate the balance between canonical Wnt signaling and noncanonical (PCP) signaling, potentially through regulation of Dsh (Simons et al. 2005; Simons and Walz 2006; Benzing et al. 2007). It has also been found that interfering with the core PCP protein Dsh causes loss of cilia in bronchial epithelial cells because of defects in docking of basal bodies (Park et al. 2008). Loss of cilia leads to defects in convergent extension of the cochlea (Jones et al. 2008). And, as mentioned, PCP proteins such as Fat4 and Vangl2 localize to the base of cilia (Ross et al. 2005; Saburi et al. 2008) in cultured cells.

What might be the role of cilia in PCP? Cilia are thought to be chemosensors and may be important in sensing PCP signals (of as yet undefined nature). Another place for cilia might be in response to PCP signals. Recent studies in the cochlea support the placement of cilia downstream of PCP signaling, as loss of cilia does not affect the polarized distribution of core PCP proteins (Jones et al. 2008). 


\section{VERTEBRATE-SPECIFIC PCP GENES}

The role of cilia in PCP and cystic kidney regulation highlights a function in PCP that is vertebrate specific. Few cells in Drosophila are ciliated, and cilia have no role in the control of PCP in the wing or eye of the fly. The role of cilia in vertebrate PCP is further underscored by the observation that many genes identified as susceptibility loci for Bardet-Biedl syndrome (BBS) show characteristic PCP defects, including open eyelids, neural tube defects and inner ear polarity disruptions (Ross et al. 2005). BBS is associated with cystic disease and obesity, and BBS proteins localize to the primary cilia.

Another class of vertebrate-specific PCP genes are related to Wnt signaling. There are 19 mammalian Wnt ligands, the majority of which signal predominantly in canonical signaling via binding to Fz receptors and activation of Dsh homologs (Dvl). Activation of Dvl disrupts the $\beta$-catenin disruption complex (composed of Axin, APC, GSK3, and CK1), resulting in stabilization of $\beta$-catenin. $\beta$ catenin can translocate to the nucleus, where it activates transcription of target genes in conjunction with TCF/LEF transcription factors (reviewed in Huang and He 2008) (see also Cadigan and Peifer 2009). In contrast, noncanonical Wnt signaling is $\beta$-catenin independent. A number of Wnts appear to regulate noncanonical signaling. For example, hair cells are misoriented in the cochlea of Wnt5a mutant mice (Qian et al. 2007) and both Wnt5 and Wnt11 are required for convergent extension in fish and frogs (Heisenberg et al. 2000; Tada and Smith 2000; Kilian et al. 2003). Surprisingly, the convergent extension defects of Wnt11 mutants can be rescued by exogenous expression of Wnt11, suggesting that Wnt11 plays a permissive role in PCP (Heisenberg et al. 2000). Recent studies suggested that the ability of a specific Wnt to signal via canonical versus noncanonical pathways may be caused by the presence of specific coreceptors or additional kinases. (Hikasa et al. 2002; Lu et al. 2004; Yamamoto et al. 2008), which may reflect the need for more complex regulation of PCP in vertebrates.
Similarly, the receptor tyrosine kinase PTK7 functions in vertebrate PCP; mutants have neural tube closure defects and inner ear PCP defects ( $\mathrm{Lu}$ et al. 2004). However, the fly homolog of PTK7, Otk, has been studied, and there are no PCP defects in either the eye or the wing in otk mutants (Winberg et al. 2001). Thus perhaps PTK7 has evolved additional functional interactions with the PCP pathway during mammalian evolution.

Of particular interest is the finding that mutations in vertebrate Scribble (Scrb) and Discs Large (Dlg) affects PCP in mammals. Scrb and Dlg are core components of the laterally acting Scrb group, which counteracts the apical-promoting Crumbs complex (reviewed in Dow and Humbert 2007; Assemat et al. 2008; Martin-Belmonte and Mostov 2008; Yamanaka and Ohno 2008). Although Drosophila Scrb and Dlg have no role in PCP, current data indicate a role for these genes in PCP control in mammals.

Scrb1 mutants have neural tube closure defects (Murdoch et al. 2003) and hair cell polarity defects in the inner ear (Montcouquiol et al. 2003). Vangl2 and Scrb1 colocalize, and there are very strong genetic interactions between Scrb1 and Vangl2: Scrb1 ${ }^{-/+}$; Vangl2 ${ }^{-/+}$mice have clear PCP defects. Interestingly, Scrb1 binds directly to Vangl2 (Montcouquiol et al. 2006), suggesting these genetic interactions are caused by a direct physical interaction between these proteins.

One possible explanation for the role of Scrb in PCP might be that it is needed for the correct localization of Vangl2. Interestingly, Scrb also binds Lgl, at a site distinct from the Vangl2 binding domain (Kallay et al. 2006), and Dsh binds Lgl (Dollar et al. 2005). Although none of these genes affect PCP in Drosophila, there are data indicating that loss of apical polarity components, such as aPKC, can weakly disrupt PCP in flies (Djiane et al. 2005). Another possible link could be via JNK, because loss of Scrb complex components in Drosophila results in activation of the JNK pathway. This points out another paradoxical aspect of PCP signaling in flies and mice. Original studies in Drosophila suggested that 
H. McNeill

JNK was a key component of PCP. These studies were based primarily on overexpression experiments (Boutros et al. 1998), and later studies showed that there were little if any PCP defects found in JNK mutants (Weber et al. 2000; Strutt et al. 2002). Therefore, in current models of PCP in flies, JNK is no longer considered to play a key role in PCP signaling. The role of JNK in mammalian PCP is generally accepted (Bloor and Kiehart 2002; Kaltschmidt et al. 2002; Kuhl 2002; Schwarz-Romond et al. 2002; Habas et al. 2003; Takeuchi et al. 2003; Cong et al. 2004; Medina et al. 2004; Unterseher et al. 2004; Schambony and Wedlich 2007; Tahinci et al. 2007; Bikkavilli et al. 2008), although some recent studies have suggested that inhibiting JNK either genetically or with pharmacological inhibitors does not affect convergent extension (Ybot-Gonzalez et al. 2007). In any case, the exact contribution of JNK to mammalian PCP is not yet clear and requires further investigation.

\section{SUMMARY AND FUTURE DIRECTIONS}

Work from flies, fish, frogs, and mice has shed light on how tissue organization is regulated in development. Yet many questions remain unanswered. How spatial information is communicated to cells in a tissue is a crucial question. Recent studies have revealed a role for Wnt11 in orienting muscle fibers (Gros et al. 2009), providing perhaps the best example of information provided by Wnts in tissue organization. But is this direct or indirect? Work from Drosophila has indicated that the Fat/Ds/Fj cassette may provide positional cues for PCP downstream of Wg, and this is a possibility that should be examined in the mouse. In no system is it certain if the Fat/ $\mathrm{Ds} / \mathrm{Fj}$ cassette is upstream of core PCP proteins: Understanding the relationship of the core PCP proteins to the Fat pathway is an important goal. And if it is upstream, how is PCP information conveyed from Fat to the core PCP proteins? Perhaps the biggest challenge of all is to understand how information from the PCP genes is transformed into cell reorganization to generate the nearly flawless planar polarization evident in the animals we see around us every day.

\section{REFERENCES}

Assemat E, Bazellieres E, Pallesi-Pocachard E, Le Bivic A, Massey-Harroche D. 2008. Polarity complex proteins. Biochim Biophys Acta 1778: 614-630.

Axelrod JD. 2001. Unipolar membrane association of Dishevelled mediates Frizzled planar cell polarity signaling. Genes Develop 15: 1182-1187.

Axelrod JD, Miller JR, Shulman JM, Moon RT, Perrimon N. 1998. Differential recruitment of Dishevelled provides signaling specificity in the planar cell polarity and Wingless signaling pathways. Genes Develop 12: 2610-2622.

Baena-Lopez LA, Baonza A, Garcia-Bellido A. 2005. The orientation of cell divisions determines the shape of Drosophila organs. Curr Biol 15: 1640-1644.

Bastock R, Strutt H, Strutt D. 2003. Strabismus is asymmetrically localised and binds to Prickle and Dishevelled during Drosophila planar polarity patterning. Development 130: 3007-3014.

Bellaiche Y, Gho M, Kaltschmidt JA, Brand AH, Schweisguth F. 2001. Frizzled regulates localization of cell-fate determinants and mitotic spindle rotation during asymmetric cell division. Nat Cell Biol 3: 50-57.

Benzing T, Simons M, Walz G. 2007. Wnt signaling in polycystic kidney disease. J Am Soc Nephrol 18: 1389-1398.

Bikkavilli RK, Feigin ME, Malbon CC. 2008. G $\alpha$ o mediates WNT-JNK signaling through dishevelled 1 and 3, RhoA family members, and MEKK 1 and 4 in mammalian cells. J Cell Sci 121: 234-245.

Bloor JW, Kiehart DP. 2002. Drosophila RhoA regulates the cytoskeleton and cell-cell adhesion in the developing epidermis. Development 129: 3173-3183.

Boutros M, Paricio N, Strutt DI, Mlodzik M. 1998. Dishevelled activates JNK and discriminates between JNK pathways in planar polarity and wingless signaling. Cell 94: 109-118.

Cadigan KM, Peifer M. 2009. Wnt signaling from development to disease: Insights from model systems. Cold Spring Harb Perspect Biol 1: a002881.

Casal J, Struhl G, Lawrence PA. 2002. Developmental compartments and planar polarity in Drosophila. Curr Biol 12: 1189-1198.

Casal J, Lawrence PA, Struhl G. 2006. Two separate molecular systems, Dachsous/Fat and Starry night/Frizzled, act independently to confer planar cell polarity. Development 133: $4561-4572$.

Chae J, Kim MJ, Goo JH, Collier S, Gubb D, Charlton J, Adler PN, Park WJ. 1999. The Drosophila tissue polarity gene starry night encodes a member of the protocadherin family. Development 126: 5421-5429.

Chen WS, Antic D, Matis M, Logan CY, Povelones M, Anderson GA, Nusse R, Axelrod JD. 2008. Asymmetric homotypic interactions of the atypical cadherin flamingo mediate intercellular polarity signaling. Cell 133: 1093-1105. 
Cho KO, Choi KW. 1998. Fringe is essential for mirror symmetry and morphogenesis in the Drosophila eye. Nature 396: $272-276$.

Choi KW, Benzer S. 1994. Rotation of photoreceptor clusters in the developing Drosophila eye requires the nemo gene. Cell 78: $125-136$.

Ciruna B, Jenny A, Lee D, Mlodzik M, Schier AF. 2006. Planar cell polarity signalling couples cell division and morphogenesis during neurulation. Nature 439: 220-224.

Collier S, Gubb D. 1997. Drosophila tissue polarity requires the cell-autonomous activity of the fuzzy gene, which encodes a novel transmembrane protein. Development 124: $4029-4037$.

Cong F, Schweizer L, Varmus H. 2004. Casein kinase Iepsilon modulates the signaling specificities of dishevelled. Mol Cell Biol 24: 2000-2011.

Curtin JA, Quint E, Tsipouri V, Arkell RM, Cattanach B, Copp AJ, Henderson DJ, Spurr N, Stanier P, Fisher EM, et al. 2003. Mutation of Celsr1 disrupts planar polarity of inner ear hair cells and causes severe neural tube defects in the mouse. Curr Biol 13: 1129-1133.

Das G, Jenny A, Klein TJ, Eaton S, Mlodzik M. 2004. Diego interacts with Prickle and Strabismus/Van Gogh to localize planar cell polarity complexes. Development 131: 4467-4476.

Davenport JR, Yoder BK. 2005. An incredible decade for the primary cilium: A look at a once-forgotten organelle. Am J Physiol 289: F1159-1169.

Deans MR, Antic D, Suyama K, Scott MP, Axelrod JD, Goodrich LV. 2007. Asymmetric distribution of pricklelike 2 reveals an early underlying polarization of vestibular sensory epithelia in the inner ear. J Neurosci 27: 3139-3147.

Devenport D, Fuchs E. 2008. Planar polarization in embryonic epidermis orchestrates global asymmetric morphogenesis of hair follicles. Nat Cell Biol 10: 1257.

Djiane A, Riou J, Umbhauer M, Boucaut J, Shi D. 2000. Role of frizzled 7 in the regulation of convergent extension movements during gastrulation in Xenopus laevis. Development 127: 3091-3100.

Djiane A, Yogev S, Mlodzik M. 2005. The apical determinants aPKC and dPatj regulate Frizzled-dependent planar cell polarity in the Drosophila eye. Cell 121: 621-631.

Dollar GL, Weber U, Mlodzik M, Sokol SY. 2005. Regulation of Lethal giant larvae by Dishevelled. Nature 437: 1376-1380.

Dominguez M, de Celis JF. 1998. A dorsal/ventral boundary established by Notch controls growth and polarity in the Drosophila eye. Nature 396: 276-278.

Dow LE, Humbert PO. 2007. Polarity regulators and the control of epithelial architecture, cell migration, and tumorigenesis. Int Rev Cytol 262: 253-302.

Eaton S. 1997. Planar polarization of Drosophila and vertebrate epithelia. Current Opinion in Cell Biol 9: 860-866.

Etheridge SL, Ray S, Li S, Hamblet NS, Lijam N, Tsang M, Greer J, Kardos N, Wang J, Sussman DJ, et al. 2008. Murine dishevelled 3 functions in redundant pathways with dishevelled 1 and 2 in normal cardiac outflow tract, cochlea, and neural tube development. PLoS Genetics 4: e1000259.
Fahmy OG, Fahmy M. 1959. New mutants report. Dros Inf Serv 33: 82-94.

Fanto M, Clayton L, Meredith J, Hardiman K, Charroux B, Kerridge S, McNeill H. 2003. The tumor-suppressor and cell adhesion molecule Fat controls planar polarity via physical interactions with Atrophin, a transcriptional co-repressor. Development 130: 763-774.

Feiguin F, Hannus M, Mlodzik M, Eaton S. 2001. The ankyrin repeat protein Diego mediates Frizzled-dependent planar polarization. Develop Cell 1: 93-101.

Ferrante MI, Romio L, Castro S, Collins JE, Goulding DA, Stemple DL, Woolf AS, Wilson SW. 2008. Convergent extension movements and ciliary function are mediated by ofd 1 , a zebrafish orthologue of the human oral-facialdigital type 1 syndrome gene. Human Mol Gen 18:289-303

Fischer E, Legue E, Doyen A, Nato F, Nicolas JF, Torres V, Yaniv M, Pontoglio M. 2006. Defective planar cell polarity in polycystic kidney disease. Nat Gen 38: 21-23.

Garoia F, Guerra D, Pezzoli MC, Lopez-Varea A, Cavicchi S, Garcia-Bellido A. 2000. Cell behaviour of Drosophila fat cadherin mutations in wing development. Mech Develop 94: 95-109.

Gho M, Schweisguth F. 1998. Frizzled signalling controls orientation of asymmetric sense organ precursor cell divisions in Drosophila. Nature 393: 178-181.

Gong Y, Mo C, Fraser SE. 2004. Planar cell polarity signalling controls cell division orientation during zebrafish gastrulation. Nature 430: 689-693.

Goto T, Keller R. 2002. The planar cell polarity gene strabismus regulates convergence and extension and neural fold closure in Xenopus. Develop Biol 247: 165-181.

Gros J, Serralbo O, Marcelle C. 2009. WNT11 acts as a directional cue to organize the elongation of early muscle fibres. Nature 457: 589-593.

Gubb D, García-Bellido A. A genetic analysis of the determination of cuticular polarity during development in Drosophila melanogaster J Embryol Exp Morphol 1982 Apr; 68: 37-57.

Gubb D, Green C, Huen D, Coulson D, Johnson G, Tree D, Collier S, Roote J. 1999. The balance between isoforms of the prickle LIM domain protein is critical for planar polarity in Drosophila imaginal discs. Genes Develop 13: 2315-2327.

Guo N, Hawkins C, Nathans J. 2004. Frizzled6 controls hair patterning in mice. Proc Natl Acad Sci 101: 9277-9281.

Habas R, Dawid IB, He X. 2003. Coactivation of Rac and Rho by Wnt/Frizzled signaling is required for vertebrate gastrulation. Genes Develop 17: 295-309.

Harris PC, Torres VE. 2008. Polycystic kidney disease. Ann Rev Med 60: 321-337.

Heisenberg CP, Tada M, Rauch GJ, Saude L, Concha ML, Geisler R, Stemple DL, Smith JC, Wilson SW. 2000. Silberblick/Wnt11 mediates convergent extension movements during zebrafish gastrulation. Nature 405: 76-81.

Hikasa H, Shibata M, Hiratani I, Taira M. 2002. The Xenopus receptor tyrosine kinase Xror2 modulates morphogenetic movements of the axial mesoderm and neuroectoderm via Wnt signaling. Development 129: 5227-5239.

Huang H, He X. 2008. Wnt/ $\beta$-catenin signaling: New (and old) players and new insights. Current Opinion Cell Biol 20: $119-125$. 
H. McNeill

Jenny A, Darken RS, Wilson PA, Mlodzik M. 2003. Prickle and Strabismus form a functional complex to generate a correct axis during planar cell polarity signaling. EMBO J 22: 4409-4420.

Jones C, Roper VC, Foucher I, Qian D, Banizs B, Petit C, Yoder BK, Chen P. 2008. Ciliary proteins link basal body polarization to planar cell polarity regulation. Nat Gen 40: 69-77.

Kallay LM, McNickle A, Brennwald PJ, Hubbard AL, Braiterman LT. 2006. Scribble associates with two polarity proteins, Lgl2 and Vangl2, via distinct molecular domains. J Cell Biochem 99: 647-664.

Kaltschmidt JA, Lawrence N, Morel V, Balayo T, Fernandez BG, Pelissier A, Jacinto A, Martinez Arias A. 2002. Planar polarity and actin dynamics in the epidermis of Drosophila. Nat Cell Biol 4: 937-944.

Kilian B, Mansukoski H, Barbosa FC, Ulrich F, Tada M, Heisenberg CP. 2003. The role of Ppt/Wnt5 in regulating cell shape and movement during zebrafish gastrulation. Mech Develop 120: 467-476.

Kibar Z, Vogan KJ, Groulx N, Justice MJ, Underhill DA, Gros P. 2001. Ltap, a mammalian homolog of Drosophila Strabismus/Van Gogh, is altered in the mouse neural tube mutant Loop-tail. Nat Genet Jul; 28: 251-255.

Kim E, Walz G. 2007. Sensitive cilia set up the kidney. Nat Med 13: 1409-1411.

Kuhl M. 2002. Non-canonical Wnt signaling in Xenopus: Regulation of axis formation and gastrulation. Sem Cell Develop Biol 13: 243-249.

Lawrence PA, Struhl G, Casal J. 2008. Planar cell polarity: A bridge too far? Curr Biol 18: R959-961.

Lu X, Borchers AG, Jolicoeur C, Rayburn H, Baker JC, Tessier-Lavigne M. 2004. PTK7/CCK-4 is a novel regulator of planar cell polarity in vertebrates. Nature 430: 93-98.

Ma D, Yang CH, McNeill H, Simon MA, Axelrod JD. 2003. Fidelity in planar cell polarity signalling. Nature 421: 543-547.

Martin-Belmonte F, Mostov K. 2008. Regulation of cell polarity during epithelial morphogenesis. Current Opinion Cell Biol 20: 227-234.

Matakatsu H, Blair SS. 2004. Interactions between Fat and Dachsous and the regulation of planar cell polarity in the Drosophila wing. Development 131: 3785-3794.

McNeill H. 2002. Planar polarity: Location, location, location. Curr Biol 12: R449-451.

McNeill H, Yang CH, Brodsky M, Ungos J, Simon MA. 1997. Mirror encodes a novel PBX-class homeoprotein that functions in the definition of the dorsal-ventral border in the Drosophila eye. Genes Develop 11: 1073-1082.

Medina A, Swain RK, Kuerner KM, Steinbeisser H. 2004. Xenopus paraxial protocadherin has signaling functions and is involved in tissue separation. EMBO $J$ 23: 3249-3258.

Montcouquiol M, Rachel RA, Lanford PJ, Copeland NG, Jenkins NA, Kelley MW. 2003. Identification of Vangl2 and Scrb1 as planar polarity genes in mammals. Nature 423: $173-177$.

Montcouquiol M, Sans N, Huss D, Kach J, Dickman JD, Forge A, Rachel RA, Copeland NG, Jenkins NA, Bogani D, et al. 2006. Asymmetric localization of Vangl2 and
Fz3 indicate novel mechanisms for planar cell polarity in mammals. J Neurosci 26: 5265-5275.

Murdoch JN, Henderson DJ, Doudney K, Gaston-Massuet C, Phillips HM, Paternotte C, Arkell R, Stanier P, Copp AJ. 2003. Disruption of scribble (Scrb1) causes severe neural tube defects in the circletail mouse. Human Mol Gen 12: 87-98.

Park M, Moon RT. 2002. The planar cell-polarity gene stbm regulates cell behaviour and cell fate in vertebrate embryos. Nat Cell Biol Jan; 4: 20-5.

Park WJ, Liu J, Sharp EJ, Adler PN. 1996. The Drosophila tissue polarity gene inturned acts cell autonomously and encodes a novel protein. Development 122: 961-969.

Park TJ, Haigo SL, Wallingford JB. 2006. Ciliogenesis defects in embryos lacking inturned or fuzzy function are associated with failure of planar cell polarity and Hedgehog signaling. Nature Genetics 38: 303-311.

Park TJ, Mitchell BJ, Abitua PB, Kintner C, Wallingford JB. 2008. Dishevelled controls apical docking and planar polarization of basal bodies in ciliated epithelial cells. Nat Gen 40: 871-879.

Patel V, Li L, Cobo-Stark P, Shao X, Somlo S, Lin F, Igarashi P. 2008. Acute kidney injury and aberrant planar cell polarity induce cyst formation in mice lacking renal cilia. Human Mol Gen 17: 1578-1590.

Piontek K, Menezes LF, Garcia-Gonzalez MA, Huso DL, Germino GG. 2007. A critical developmental switch defines the kinetics of kidney cyst formation after loss of Pkd1. Nat Med 13: 1490-1495.

Praetorius HA, Spring KR. 2003. The renal cell primary cilium functions as a flow sensor. Current Opinion NephrolHypertension 12: 517-520.

Qian D, Jones C, Rzadzinska A, Mark S, Zhang X, Steel KP, Dai X, Chen P. 2007. Wnt5a functions in planar cell polarity regulation in mice. Develop Biol 306: 121-133.

Rawls AS, Guinto JB, Wolff T. 2002. The cadherins fat and dachsous regulate dorsal/ventral signaling in the Drosophila eye. Curr Biol 12: 1021-1026.

Ross AJ, May-Simera H, Eichers ER, Kai M, Hill J, Jagger DJ, Leitch CC, Chapple JP, Munro PM, Fisher S, et al. 2005. Disruption of Bardet-Biedl syndrome ciliary proteins perturbs planar cell polarity in vertebrates. Nat Gen 37: 1135-1140.

Saburi S, Hester I, Fischer E, Pontoglio M, Eremina V, Gessler M, Quaggin SE, Harrison R, Mount R, McNeill H. 2008. Loss of Fat 4 disrupts PCP signaling and oriented cell division and leads to cystic kidney disease. Nat Gen 40: $1010-1015$.

Schambony A, Wedlich D. 2007. Wnt-5A/Ror2 regulate expression of XPAPC through an alternative noncanonical signaling pathway. Develop Cell 12: 779-792.

Schwarz-Romond T, Asbrand C, Bakkers J, Kuhl M, Schaeffer HJ, Huelsken J, Behrens J, Hammerschmidt M, Birchmeier W. 2002. The ankyrin repeat protein Diversin recruits Casein kinase Iepsilon to the $\beta$-catenin degradation complex and acts in both canonical Wnt and Wnt/JNK signaling. Genes Develop 16: 2073-2084.

Simon MA. 2004. Planar cell polarity in the Drosophila eye is directed by graded Four-jointed and Dachsous expression. Development 131: 6175-6184. 
Simons M, Walz G. 2006. Polycystic kidney disease: Cell division without a c(l)ue? Kidney Int 70: 854-864.

Simons M, Gloy J, Ganner A, Bullerkotte A, Bashkurov M, Kronig C, Schermer B, Benzing T, Cabello OA, Jenny A, et al. 2005. Inversin, the gene product mutated in nephronophthisis type II, functions as a molecular switch between Wnt signaling pathways. Nat Gen 37: 537-543.

Sopko R, McNeill H. 2009. The Skinny on Fat: An enormous cadherin regulating cell adhesion, tissue growth and planar cell polarity. Current Opinions Cell Biol (in press).

Sopko R, Silva E, Clayton L, Gardano L, Barrios-Rodiles M, Wrana J, Varelas X, Arbouzova NI, Shaw S, Saburi S, et al. 2009. Phosphorylation of the Tumor Suppressor Fat Is Regulated by Its Ligand Dachsous and the Kinase Discs Overgrown. Curr Biol (in press) PMID: 19540118.

Strutt D, Strutt H. 2007. Differential activities of the core planar polarity proteins during Drosophila wing patterning. Develop Biol 302: 181-194.

Strutt H, Strutt D. 2002. Nonautonomous planar polarity patterning in Drosophila: Dishevelled-independent functions of frizzled. Develop Cell 3: 851-863.

Strutt H, Strutt D. 2003. EGF signaling and ommatidial rotation in the Drosophila eye. Curr Biol 13: 1451-1457.

Strutt H, Strutt D. 2008. Differential stability of flamingo protein complexes underlies the establishment of planar polarity. Curr Biol 18: 1555-1564.

Strutt D, Warrington SJ. 2008. Planar polarity genes in the Drosophila wing regulate the localisation of the FH3-domain protein Multiple Wing Hairs to control the site of hair production. Development 135: 3103-3111.

Strutt D, Johnson R, Cooper K, Bray S. 2002. Asymmetric localization of frizzled and the determination of notchdependent cell fate in the Drosophila eye. Curr Biol 12: 813-824.

Strutt H, Price MA, Strutt D. 2006. Planar polarity is positively regulated by casein kinase I epsilon in Drosophila. Curr Biol 16: 1329-36.

Tada M, Kai M. 2009. Noncanonical Wnt/PCP signaling during vertebrate gastrulation. Zebrafish 6: 29-40.

Tada M, Smith JC. 2000. Xwnt11 is a target of Xenopus Brachyury: Regulation of gastrulation movements via Dishevelled, but not through the canonical Wnt pathway. Development 127: 2227-2238.

Tahinci E, Thorne CA, Franklin JL, Salic A, Christian KM, Lee LA, Coffey RJ, Lee E. 2007. Lrp6 is required for convergent extension during Xenopus gastrulation. Development 134: 4095-4106.

Takeuchi M, Nakabayashi J, Sakaguchi T, Yamamoto TS, Takahashi H, Takeda H, Ueno N. 2003. The prickle-related gene in vertebrates is essential for gastrulation cell movements. Curr Biol 13: 674-679.

Taylor J, Abramova N, Charlton J, Adler PN. 1998. Van Gogh: A new Drosophila tissue polarity gene. Genetics 150: $199-210$.

Torban E, Patenaude AM, Leclerc S, Rakowiecki S, Gauthier S, Andelfinger G, Epstein DJ, Gros P. 2008. Genetic interaction between members of the Vangl family causes neural tube defects in mice. Proc Natl Acad Sci 105: $3449-3454$
Tree DR, Shulman JM, Rousset R, Scott MP, Gubb D, Axelrod JD. 2002. Prickle mediates feedback amplification to generate asymmetric planar cell polarity signaling. Cell 109: 371-381.

Unterseher F, Hefele JA, Giehl K, De Robertis EM, Wedlich D, Schambony A. 2004. Paraxial protocadherin coordinates cell polarity during convergent extension via Rho A and JNK. EMBO J 23: 3259-3269.

Usui T, Shima Y, Shimada Y, Hirano S, Burgess RW, Schwarz TL, Takeichi M, Uemura T. 1999. Flamingo, a seven-pass transmembrane cadherin, regulates planar cell polarity under the control of Frizzled. Cell 98: 585-595.

Vinson CR, Adler PN. 1987. Directional non-cell autonomy and the transmission of polarity information by the frizzled gene of Drosophila. Nature 329: 549-551.

Wallingford JB, Rowning BA, Vogeli KM, Rothbacher U, Fraser SE, Harland RM. 2000. Dishevelled controls cell polarity during Xenopus gastrulation. Nature 405: 81-85.

Wang J, Mark S, Zhang X, Qian D, Yoo SJ, Radde-Gallwitz K, Zhang Y, Lin X, Collazo A, Wynshaw-Boris A, et al. 2005. Regulation of polarized extension and planar cell polarity in the cochlea by the vertebrate PCP pathway. Nat Gen 37: 980-985.

Wang Y, Guo N, Nathans J. 2006. The role of Frizzled3 and Frizzled6 in neural tube closure and in the planar polarity of inner-ear sensory hair cells. J Neurosci 26: 2147-2156.

Weber U, Paricio N, Mlodzik M. 2000. Jun mediates Frizzled-induced R3/R4 cell fate distinction and planar polarity determination in the Drosophila eye. Development 127: 3619-3629.

Winberg ML, Tamagnone L, Bai J, Comoglio PM, Montell D, Goodman CS. 2001. The transmembrane protein Off-track associates with Plexins and functions downstream of Semaphorin signaling during axon guidance. Neuron 32: 53-62.

Wolff T, Rubin GM. 1998. Strabismus, a novel gene that regulates tissue polarity and cell fate decisions in Drosophila. Development 125: 1149-1159.

Wong HC, Bourdelas A, Krauss A, Lee HJ, Shao Y, Wu D, Mlodzik M, Shi DL, Zheng J. 2003. Direct binding of the PDZ domain of Dishevelled to a conserved internal sequence in the C-terminal region of Frizzled. Mol Cell 12: $1251-1260$.

Wu J, Mlodzik M. 2008. The frizzled extracellular domain is a ligand for Van Gogh/Stbm during nonautonomous planar cell polarity signaling. Develop Cell 15: 462-469.

Yamamoto S, Nishimura O, Misaki K, Nishita M, Minami Y, Yonemura S, Tarui H, Sasaki H. 2008. Cthrc1 selectively activates the planar cell polarity pathway of Wnt signaling by stabilizing the Wnt-receptor complex. Develop Cell 15: 23-36.

Yamanaka T, Ohno S. 2008. Role of $\mathrm{Lgl} / \mathrm{Dlg} / \mathrm{Scribble}$ in the regulation of epithelial junction, polarity and growth. Front Biosci 13: 6693-6707.

Yang CH, Simon MA, McNeill H. 1999. Mirror controls planar polarity and equator formation through repression of fringe expression and through control of cell affinities. Development 126: 5857-5866. 


\section{H. McNeill}

Yang CH, Axelrod JD, Simon MA. 2002. Regulation of Frizzled by fat-like cadherins during planar polarity signaling in the Drosophila compound eye. Cell 108: $675-688$.

Ybot-Gonzalez P, Savery D, Gerrelli D, Signore M, Mitchell CE, Faux CH, Greene ND, Copp AJ. 2007 Convergent extension, planar-cell-polarity signalling and initiation of mouse neural tube closure. Development 134:789-799.

Yoder BK. 2007. Role of primary cilia in the pathogenesis of polycystic kidney disease. JAm Soc Nephrol 18: 1381-1388.

Zeidler MP, Perrimon N, Strutt DI. 1999. The four-jointed gene is required in the Drosophila eye for ommatidial polarity specification. Curr Biol 9: 1363-1372. 


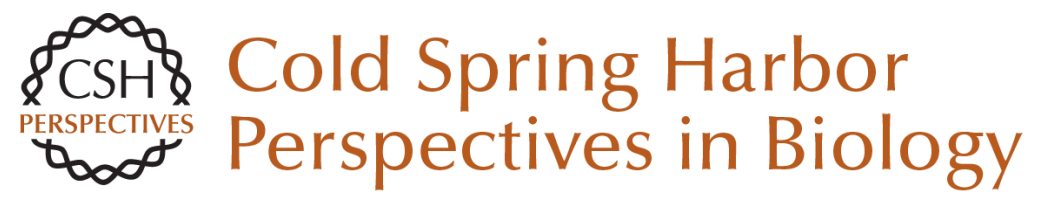

\section{Planar Cell Polarity: Keeping Hairs Straight Is Not So Simple}

Helen McNeill

Cold Spring Harb Perspect Biol 2010; doi: 10.1101/cshperspect.a003376 originally published online September 23, 2009

\section{Subject Collection Cell-Cell Junctions}

Vascular Endothelial (VE)-Cadherin, Endothelial Adherens Junctions, and Vascular Disease Maria Grazia Lampugnani, Elisabetta Dejana and Costanza Giampietro

Adherens Junctions and Desmosomes Coordinate Mechanics and Signaling to Orchestrate Tissue Morphogenesis and Function: An Evolutionary Perspective Matthias Rübsam, Joshua A. Broussard, Sara A. Wickström, et al.

Cell-Cell Contact and Receptor Tyrosine Kinase Signaling Christine Chiasson-MacKenzie and Andrea I. McClatchey

Hold Me, but Not Too Tight---Endothelial Cell-Cell Junctions in Angiogenesis Anna Szymborska and Holger Gerhardt

\section{Connexins and Disease} Mario Delmar, Dale W. Laird, Christian C. Naus, et al.

\section{Cell Junctions in Hippo Signaling}

Ruchan Karaman and Georg Halder

Loss of E-Cadherin-Dependent Cell-Cell Adhesion and the Development and Progression of Cancer Heather C. Bruner and Patrick W.B. Derksen
Signaling by Small GTPases at Cell-Cell Junctions: Protein Interactions Building Control and Networks Vania Braga

Making Connections: Guidance Cues and Receptors at Nonneural Cell-Cell Junctions Ian V. Beamish, Lindsay Hinck and Timothy E. Kennedy

The Cadherin Superfamily in Neural Circuit Assembly James $D$. Jontes

Mechanosensing and Mechanotransduction at Cell-Cell Junctions Alpha S. Yap, Kinga Duszyc and Virgile Viasnoff

Beyond Cell-Cell Adhesion: Sensational

Cadherins for Hearing and Balance Avinash Jaiganesh, Yoshie Narui, Raul Araya-Secchi, et al.

Cell-Cell Junctions Organize Structural and Signaling Networks Miguel A. Garcia, W. James Nelson and Natalie Chavez

Cell Biology of Tight Junction Barrier Regulation and Mucosal Disease Aaron Buckley and Jerrold R. Turner

For additional articles in this collection, see http://cshperspectives.cshlp.org/cgi/collection/

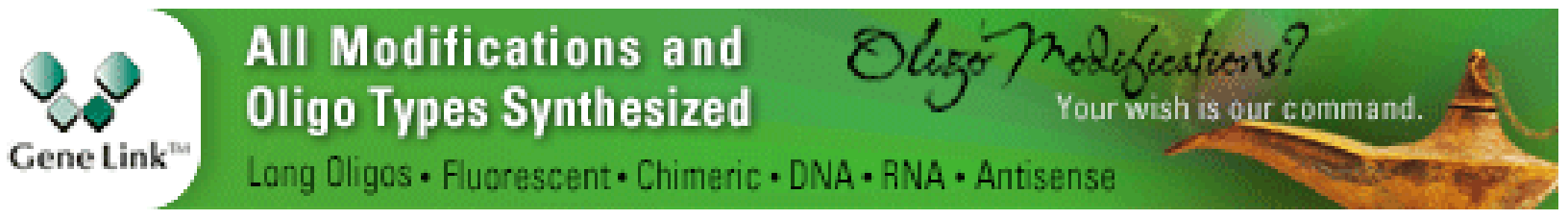


Desmosomes and Intermediate Filaments: Their Consequences for Tissue Mechanics Mechthild Hatzfeld, René Keil and Thomas M. Magin
Integration of Cadherin Adhesion and

Cytoskeleton at Adherens Junctions

René Marc Mège and Noboru Ishiyama

For additional articles in this collection, see http://cshperspectives.cshlp.org/cgi/collection/

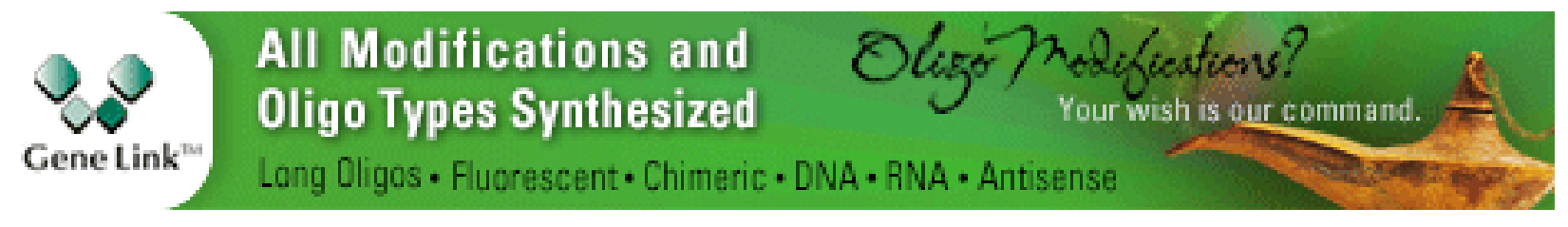

Copyright @ 2010 Cold Spring Harbor Laboratory Press; all rights reserved 